\title{
USO DAS TECNOLOGIAS DIGITAIS EM ATIVIDADES DIDÁTICAS NAS SÉRIES INICIAIS
}

\section{Resumo:}

\author{
Lilian Medianeira Prieto* \\ Maria do Carmo Barbosa Trevisan ${ }^{* *}$ \\ Maria Isabel Danesi*** \\ Gilse A.Morgental Falkembach ${ }^{* * * *}$
}

Este artigo trata do uso das tecnologias digitais em atividades didáticas com alunos das séries iniciais, a importância dos materiais educativos digitais e das práticas pedagógicas inovadoras para otimizar o processo de ensino e aprendizagem. Mostra 3 aplicações desenvolvidas com o Sistema de Autoria TOOLBOOK.

Palavras-chave: Informática na Educação, atividades digitais, materiais educativos, software educacional, séries iniciais.

\section{THE USE OF THE DIGITAL TECHNOLOGIES IN DIDACTIC ACTIVITIES IN THE INITIAL SERIES}

\begin{abstract}
This article treats of the use of the digital technologies in didactic activities with students of the initial series, the importance of the digital educational materials and of the innovative pedagogic practices for to optimize the teaching process and learning. Display 3 applications developed with the Author System TOOLBOOK.
\end{abstract}

Keywords: Informatics in Education, digital activities, educational materials, educational software, initial series

\section{Introdução}

Nos dias de hoje, as tecnologias digitais vêm demonstrando que é possível o desenvolvimento de um novo paradigma educacional. Cada vez mais cedo as crianças estão em contato com as novas tecnologias. Este fator pode trazer consigo mudanças nos modos de comunicação e de interação. Essas mudanças serão positivas, desde que aconteça uma re-contextualização das habilidades comunicativas, pois, segundo (Avala, 2003), o ciberespaço oferece oportunidades que acabam com obstáculos como tempo e espaço e através do acesso e do domínio das novas tecnologias são desenvolvidas novas competências fundamentais: como o senso crítico; o pensamento hipotético e dedutivo; as faculdades de observação e de pesquisa; o julgamento; a capacidade de memorizar e classificar; a leitura e a análise de textos e de imagens; a imaginação; a representação em redes e os procedimentos e estratégias de comunicação.

A Educação, influenciada pela globalização, avança no desenvolvimento dos indivíduos. As novas tecnologias, como a Internet, forçam a adaptação ao meio e ao ambiente social. O professor se torna um elo de conhecimento dessas tecnologias inovadoras, transformando o processo de aprendizagem. Os recursos tecnológicos usados na Educação devem caminhar buscando um objetivo único: a otimização do processo de ensino e aprendizagem. $\mathrm{O}$ uso das tecnologias digitais possibilita a transformação dos velhos paradigmas de educação, propiciando atividades pedagógicas inovadoras. O computador tem que ser visto como uma ferramenta de ensino e deve ser o facilitador da aprendizagem, buscando fascinar o aluno para as novas descobertas. Segundo (Figueredo, 2003): 
A tecnologia é um instrumento capaz de aumentar a motivação dos alunos, se a sua utilização estiver inserida num ambiente de aprendizagem desafiador. Não é por si só um elemento motivador. Se a proposta de trabalho não for interessante, os alunos rapidamente perdem a motivação.(Introdução aos Parâmetros Curriculares Nacionais, 2001).

Daí a importância do desenvolvimento de software educacional de qualidade técnica e pedagógica. É preciso que os profissionais da área educacional imponham uma pedagogia adequada, interessante, mais de acordo com a realidade do aluno e com o novo paradigma que está surgindo. Os educadores não devem deixar a responsabilidade da criação de material didático às empresas. Para que o material instrucional seja efetivamente um aliado didático é preciso que o professor o use calcado em uma prática pedagógica motivadora. A Informática na Educação subsidia o diálogo entre os profissionais da área técnica, da Psicologia e da Educação o que possibilita a criação de materiais instrucionais de qualidade.

\section{As tecnologias digitais na Educação}

As tecnologias digitais estão na Educação através de aplicativos educacionais que podem ser: desde simples atividades de exercício e prática, que se caracterizam pela realização de atividades repetitivas para treinar habilidades ou recapitular conteúdos já trabalhados; como tutoriais sobre determinado conteúdo; ou softwares do tipo enciclopédias para consultas; ou ainda softwares de simulação, que servem para mostrar efeitos que não poderiam ser gerados na realidade, criando modelos do mundo real $\mathrm{e}$ permitindo a exploração de situações fictícias, de experiências impossíveis ou muito complicadas de serem obtidas. Têm-se também os jogos educacionais, que de acordo com (Tajra, 1998), são ferramentas disponíveis para o professor utilizar em suas aulas, tornando-as mais divertidas e animadas; os softwares de testes com grau de dificuldades variadas, apresentadas de forma randômica com ou sem referência cruzada. Os escores dos alunos são computados de forma automática e é possível apresentar as estatísticas relacionadas ao desempenho. Existem pacotes de softwares de testes disponíveis comercialmente tal como o Hotpotatoes. As histórias infantis digitais também representam um material didático rico, com funções cognitivas, que auxiliam na construção do conhecimento. Elas são intrinsecamente motivadoras, normalmente, baseadas em fatores sociais e culturais, todos relacionados ao ato de brincar e imitar com características de fantasia, de desafios, de curiosidade e de controle. Todos esses materiais educativos para cumprirem com o objetivo de recurso didático precisam ser utilizados por professores que saibam explorar a potencialidade do software selecionando as atividades específicas para cada fase de aprendizagem e possibilitando ao aluno trabalhar através da descoberta. O computador é um recurso cuja eficácia depende daqueles que o usam, daí ser necessário que o professor esteja capacitado e que haja mudanças nas práticas pedagógicas.

O software educacional com atividades de avaliação deve fornecer ao aluno um feedback. Caso a resposta de uma questão não esteja certa, ocorre o erro e o processo é reiniciado. Esse ciclo de ações leva a reflexão sobre os conceitos, estratégias, erros cometidos e possíveis soluções às questões apresentadas. A partir de (Valente,1995): "Isso desenvolve um processo traduzido pelo ciclo "descrição-execução-reflexãodepuração".

O erro (bugs) nesse processo tem um papel importante e não é mais motivo para punição, intimidação ou frustração, pois, a reflexão sobre os mesmos é que vai levar a compreensão e a proposição de novas estratégias para a sua solução. Sendo assim, segundo (Almeida, 2000), o ciclo descrição-execução-reflexão-depuração é 
característica da atividade computacional, transferível e aplicável nas práticas discentes e docentes.

O professor no ambiente construcionista tem como função, segundo o mesmo autor "promover a aprendizagem do aluno para que este possa construir o conhecimento dentro de um ambiente que o desafie e o motive para a exploração, a reflexão, a depuração de idéias e a descoberta". Para isto é necessário um ambiente cooperativo, onde o professor conheça as potencialidades e as experiências anteriores de seus alunos, organize situações significativas de aprendizagem e torne-se também um aprendiz.

\section{Desenvolvimento humano e aprendizagem}

Piaget através de seus estudos deu origem a teoria dos estágios, em que distinguiu quatro deles como essenciais ao desenvolvimento humano desde o nascimento até a fase adulta. Esses estágios são: sensório-motor, pré-operacional (fase do pensamento simbólico, fase do pensamento intuitivo), fase das operações concretas e das operações formais.

O primeiro estágio, sensório-motor, ocorre do nascimento da criança até os dois anos de idade. Através de seus movimentos e da sensibilidade a criança na suas atividades irá perceber o mundo e diferenciar-se dele.

O segundo estágio é o pré-operacional e caracteriza-se pela fase do pensamento simbólico, em que a criança pode imitar alguém ou algum objeto em situação diferente da original e sem nenhum modelo presente; depois, passa a brincar de forma simbólica, imaginando determinada situação e agindo como se ela estivesse acontecendo realmente. Nessa fase surge a fala. Ainda no estágio pré-operatório, há a fase do pensamento intuitivo, em que suas deduções são intuitivas baseadas nas observações.

O desenvolvimento mental da criança nesta fase, segundo (Piaget, 1975) pode ser sensivelmente estimulado através dos jogos. O jogo de complexidade relativa oportuniza a troca de idéias entre crianças que trabalham em conjunto ou, se a criança trabalha sozinha, estimula o pensamento dela consigo mesma. E se pensar é dialogar consigo mesmo, o jogo possibilita o diálogo, o intermedia e o instiga. Há um movimento complexo do pensamento da ação do sujeito, coordenado por uma linha de pensamento, em xeque com a lógica do jogo e do desafio.

O terceiro estágio, designado fase das operações concretas acontece dos sete aos doze anos de idade e tem como principal característica o uso do pensamento lógico e do raciocínio. Isto significa que a criança deve manipular materiais concretos, para melhor compreendê-los, mas na falta deles deve poder imaginá-los.

Os jogos ou brinquedos pedagógicos desenvolvidos com a intenção explícita de provocar uma aprendizagem significativa, estimula a construção de um novo conhecimento e, principalmente, desperta o desenvolvimento de uma habilidade operatória, ou seja, uma aptidão ou capacidade cognitiva e apreciativa específica, que possibilita a compreensão e a intervenção do indivíduo nos fenômenos sociais e culturais e o ajuda a construir conexões.

Sendo assim, segundo (Antunes, 1999) os jogos ou as atividades didáticas podem vir a estimular mais explicitamente uma das inteligências, conforme abaixo: 
- Inteligência Lingüística - Estimula: Vocabulário; Fluência verbal; Gramática; Alfabetização e Memória verbal.

- Inteligência Lógico-Matemática - Estimula: Conceituação; Sistemas de numeração; Pensamento lógico.

- Inteligência Espacial - Estimula: Percepção auditiva; Orientação espacial;Orientação temporal; Criatividade e Alfabetização cartográfica.

- Inteligência Musical - Estimula: Percepção auditiva; Discriminação de ruídos; Compreensão de sons; Discriminação de sons e Estrutura rítmica.

- Inteligência Cinestésico Corporal - Estimula: Motricidade e coordenação manual; Coordenação viso motora e tátil; Percepção de formas; Percepção de fundo; Percepção de peso e tamanhos; Paladar e audição.

- Inteligência Naturalista - Estimula: Curiosidade; Exploração; Descoberta; Interação e Aventuras.

- Inteligência Pictórica - Estimula: Reconhecimento de objetos; cores; formas e tamanhos; Percepção de fundo e Percepção viso motora.

- Inteligência Pessoal - Estimula: Percepção Corporal; Autoconhecimento e relacionamento social; Administração das emoções; Ética e empatia; Automotivação e comunicação interpessoal.

O quarto estágio do desenvolvimento intelectual humano denomina-se fase das operações formais e desenvolve-se dos doze aos quinze anos de idade. Durante esse período, o indivíduo consegue pensar hipotética e dedutivamente.

É importante salientar que todos estes estágios entrelaçam-se servindo de trampolim para novas etapas do desenvolvimento cognitivo, e a interação com o meio poderá retardar ou acelerar o processo de transição de um estágio para outro. Portanto, é importante para o professor conhecê-los para identificá-los e intervir de forma conveniente no processo de aprendizagem, visando auxiliar no desenvolvimento cognitivo do educando. O uso adequado dos recursos oferecidos pelas tecnologias digitais, através de materiais educativos multimídia, pode auxiliar nesse processo.

(Piaget, 1978), definiu, através da Epistemologia Genética as alterações de ordem física que modificam o indivíduo quando ele interage com o objeto. Defendeu o universalismo do conhecimento, ou seja, que as estruturas cognitivas para o desenvolvimento do conhecimento são as mesmas para qualquer indivíduo. Mais tarde, Vigotsky veio contrapor Piaget, afirmando que na verdade a cultura seria determinante na aquisição do conhecimento e, portanto, nem todos os indivíduos teriam as mesmas condições de aprender.

Vigotsky propôs dois níveis de desenvolvimento do indivíduo: o nível de conhecimento real, ou seja, aquilo que o sujeito pode fazer sozinho e, o nível de desenvolvimento potencial, aquilo que o sujeito pode fazer e aprender no relacionamento com as outras pessoas. A zona de desenvolvimento proximal seria a união entre estes dois níveis de conhecimentos; é um domínio psicológico em constante transformação: aquilo que uma criança é capaz de fazer hoje com a ajuda de alguém conseguirá fazer sozinha amanhã.

Existe a expressão sócio construtivismo ou sócio interacionismo para distinguir a teoria de Vygotski do construtivismo de Piaget, pois, segundo alguns autores ambos são construtivistas uma vez que sustentam que a inteligência é construída a partir das relações recíprocas do homem com o meio ambiente. Para Vygotski o meio tem sempre significados culturais que são aprendidos pelas crianças através dos mediadores. Este 4 
fator cultural valorizado por Vygotski e com pouco valor para Piaget contribui para a diferença entre eles. Outra diferença é quanto à seqüência dos processos de aprendizagem e de desenvolvimento mental. Vygotski afirma que a aprendizagem é que gera o desenvolvimento, já Piaget afirma que é o desenvolvimento das estruturas mentais que leva à aprendizagem. A partir de (Vygotski,1988), os vygotskianos, afirmam que:

A Educação não fica a espera do desenvolvimento intelectual da criança e que a função da escola, tendo o professor como mediador da aprendizagem, é levar o aluno adiante, pois quanto mais ele aprende mais se desenvolve mentalmente.

\section{Fases da Alfabetização}

Em um nível anterior ao da construção da leitura e escrita, a criança pensa que para cada objeto há uma grafia específica, não havendo relação entre o som da fala e a escrita. Segundo (Ferreiro, 1994), este é o nível pré-silábico da psicogênese, em que a criança pode representar a escrita por desenhos (Pré- Silábico 1) ou então usar sinais gráficos como letras e/ou números, observando critérios de disposição e quantidade mínima de sinais guardando relação com o tamanho do objeto que deseja representar (Pré- Silábico 2). Quando alcança o nível Silábico passa a fazer relações entre o som da fala e o que deseja escrever. Neste nível psicogenético, representa um sinal gráfico para cada sílaba oral que tenha ou não tenha valor sonoro: $\mathrm{AAO}=\mathrm{MACACO}$. Ao perceber suas hipóteses incompletas, a criança passa por um imenso conflito, denominado nível intermediário. A fase Alfabética (uma letra para cada fonema) demonstra que a criança compreendeu, adquiriu esse código e passa escrever guardando ainda estreita relação entre a língua escrita e a língua oral.

A construção alfabética, inicialmente tem como características: a criança pensa que a escrita representa o som oral e escreve como fala, correspondendo claramente uma letra para cada fonema; pensa que todas as sílabas são constituídas por duas letras e tenta enquadrar a sua escrita a esta hipótese; generaliza uma forma freqüente de escrever as sílabas - consoante + vogal $($ ex. RAMAZE $=$ armazém ou MEPADA = empada); vogal nasal e grupos consonantais são questões não consideradas na maioria dos escritos das crianças alfabéticas; não separa as palavras na produção de frases e/ou textos; fazem adequação fonética denotando nesta hipótese que existem grafemas equivalentes (ex. CASA, CAZAMENTO); não usam letras maiúsculas, minúsculas e sinais de pontuação.

Vencida a aquisição do código escrito chega-se à psicogênese da ortografia, ou seja, o aluno chega ao nível de conceitualização. Segundo (Grossi, 2001), as principais dificuldades que um aluno encontra para construir a convenção social da escrita são:

- O l e o $\mathbf{r}$ intercalados ou encontros vocálicos. Ex. professora, gravata, floresta;

- O n, r, l e s pós - vocálicos. Ex. dente, porta, calça, poste;

- $\mathbf{Z}$ ou $\mathbf{S}$ - Ex. casa, tesoura, fazenda;

- L ou LH - Ex. família ou famílha?

- G ou J - Ex. Girafa ou Jirafa?

- Como se chega ao NH?

- O l, u e o no final das palavras. Ex. chapél, chapéu ou chapéo?

- O C com som de $\mathbf{Q}$. Ex. Porce (porque);

- A questão do "e" e do "é";

- O sinal da nasalização é o , n ou m?

- A questão do am e ão. Ex. estudaram ou estudarão? 
- Troca do e pelo i, ou do o pelo $\mathbf{u}$;

- O emprego do $\mathbf{H}$;

- É Chinelo ou Xinelo?

- É com Ç, S ou SS?

- A questão do que, gue e gui;

- Os sons do $\mathbf{x}$.

A leitura é uma grande arma para se chegar a uma escrita ortográfica, porém é necessário que o aluno seja o primeiro leitor de tudo o que escreve, para que possa ser o seu próprio revisor. No processo de ortografização, o aluno se dá conta que a linguagem oral é uma coisa e a linguagem escrita é outra, e embora tenham relações, nem sempre se escreve como se fala. Para isso é necessário primeiramente desenvolver o gosto e o prazer pela leitura e escrita, para depois o professor vir a questionar a ortografia. Como matéria-prima para formar palavras as atividades digitais com sílabas variadas levam a criança a abordá-la em sua construção específica e ajudam muito a ortografia. Porém, para que as atividades, de uma forma lúdica, auxiliem o aluno é preciso que o professor tenha conhecimento do nível em que se encontra a criança para auxiliar no desenvolvimento de suas potencialidades e habilidades, proporcionando-lhe situações significativas de aprendizagem, que venham enriquecer suas experiências e contribuir para a construção do conhecimento.

\section{Multimídia e atividades digitais}

A multimídia é a combinação de texto, som, imagem, animação e vídeo, ou seja, incorpora todas as mídias existentes para representar uma informação. É, por isso, uma forma poderosa de comunicação, pois ganha e mantém a atenção e o interesse do aluno e com isto promove a retenção da informação. Para a Educação, uma atividade didática multimídia bem empregada, é um recurso poderoso, pois, estimula todos os sentidos e pode oferecer uma experiência melhor que qualquer outra mídia sozinha.

As atividades digitais multimídia, na sua maioria, possuem grande apelo visual, acabam encantando pelo layout com cores vibrantes, som e movimento e fascinando até o professor que muitas vezes tem um conhecimento limitado de computação e se impressiona com a interface colorida, o áudio e os vídeos, principalmente nos produtos direcionados às crianças. Os empresários contam com isto para venderem seus produtos. É preciso uma análise criteriosa, antes de se usar materiais multimídia, ditos educacionais, pois, muitos destes produtos são desenvolvidos sem a orientação de profissionais como pedagogos, psicólogos, tecnólogos educacionais e por isso mesmo não possuem o comprometimento com o processo de ensino e aprendizagem.

\section{Aplicações multimídias para pré-escola e séries iniciais}

Baseados em Piaget e Vygotski, os estudos, sobre a psicogênese da língua escrita, desenvolvidos por (Ferreiro e Teberosky, 1994) comprovam que a criança reconstrói o código lingüístico e reflete sobre a escrita. Sendo assim, conhecendo-se os diversos níveis conceituais lingüísticos da criança, foi possível criar aplicações com atividades para que ela possa desestruturar sua concepção e construir o conhecimento da base alfabética escrita.

Para o desenvolvimento das aplicações foi escolhido o Sistema de Autoria TOOLBOOK, desenvolvido pela Asymetrix no início da década de 90. É um software específico para o desenvolvimento de aplicações hipermídias. É um sistema baseado em objetos que ao 
serem submetidos a um evento executam o que é definido por um script. Permite criar uma aplicação que é um arquivo.tbk e que faz metáfora com um livro. Trabalha em 2 modos: autor e leitor. Importa e agrega mídias geradas em aplicativos específicos. Os objetos possuem suas propriedades e podem ou não possuir um script. O script é um conjunto de instruções, escritas na linguagem de programação do sistema e é associado ao objeto. Na área educacional, o TOOLBOOK, permite a professores sem maiores conhecimentos de programação criar aplicações, com hipertextos e recursos de multimídia, com uma certa facilidade.

Através desse sistema foram criadas atividades lúdicas, relacionadas às fases da alfabetização: pré-silábica; silábica; e alfabética, e ainda atividades com situações desafiadoras que fornecem ao aluno, já alfabetizado, elementos para pensar e aprender.

$1^{\text {a }}$ aplicação - é um material didático, na forma de jogo que tem como objetivo principal oportunizar que a criança, ao executar as atividades propostas na carta selecionada randomicamente, exercite a exploração espacial, a coordenação motora e a percepção visual, possibilitando o reconhecimento dos algarismos (de zero a seis), as vogais e as consoantes. São usadas as teclas relacionadas às setas para cumprir o que está sendo solicitado na carta sorteada. Foram utilizadas as mídias de texto, som e imagem em cada tela para onde é feito o desvio, enfatizando o reconhecimento das letras e dos algarismos, através da grafia, de imagem e de áudio.

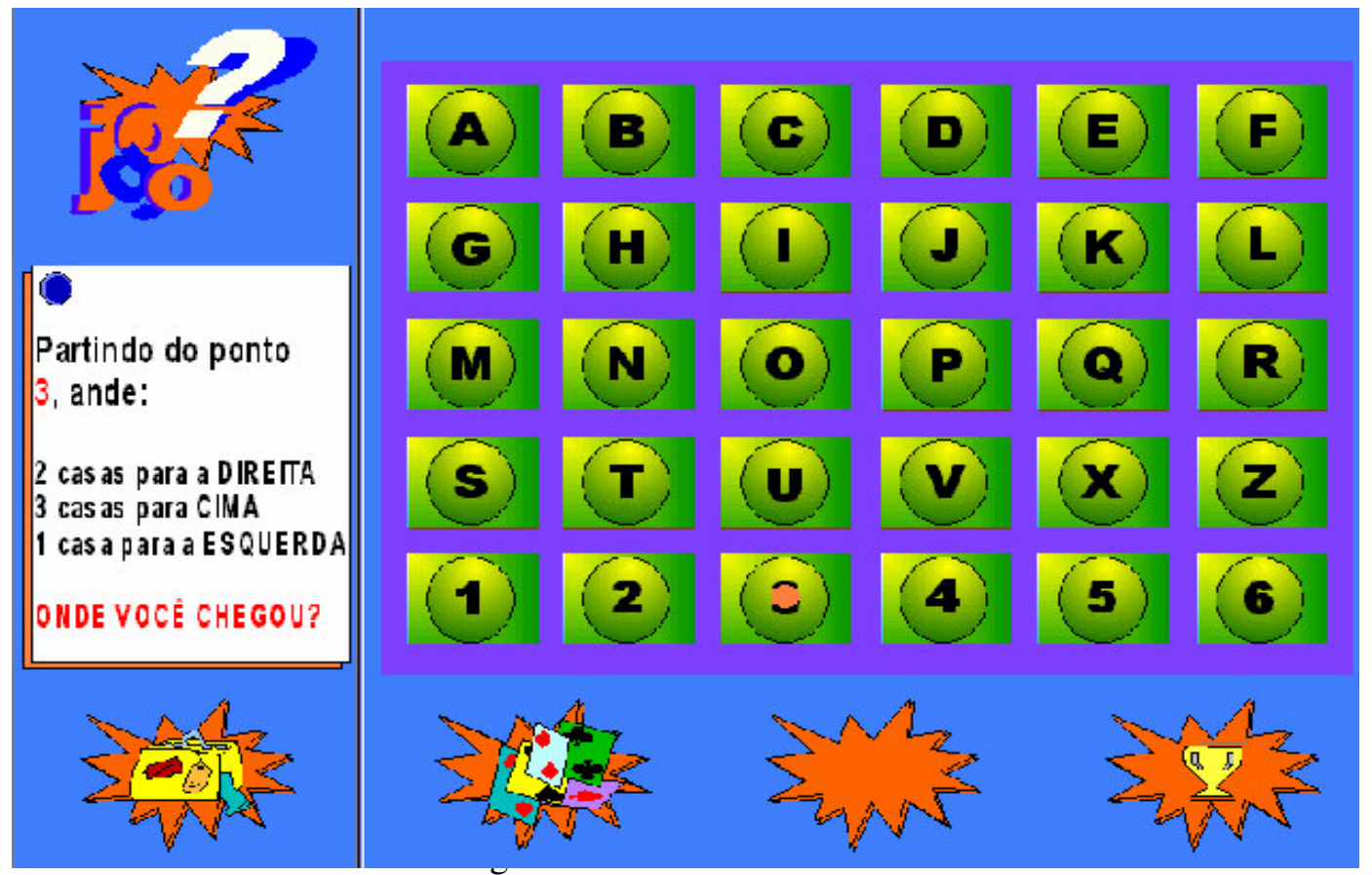

Figura 1 - Tela do jogo para reconhecimento das letras e algarismos 


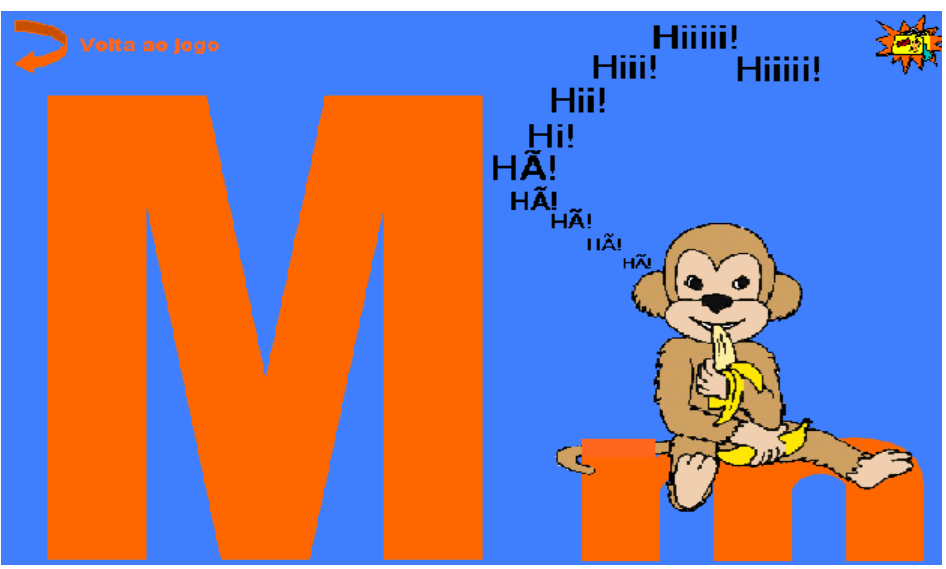

Figura 2 - Tela da letra M

$2^{\mathrm{a}}$ aplicação - é um material educacional, para o uso das tecnologias digitais, como recurso didático auxiliar no processo de ensino e aprendizagem de crianças de $1^{\mathrm{a}}$ e $2^{\mathrm{a}}$ séries do ensino fundamental. Apresenta 7 tipos de atividades com objetivos específicos explicitados na aplicação.

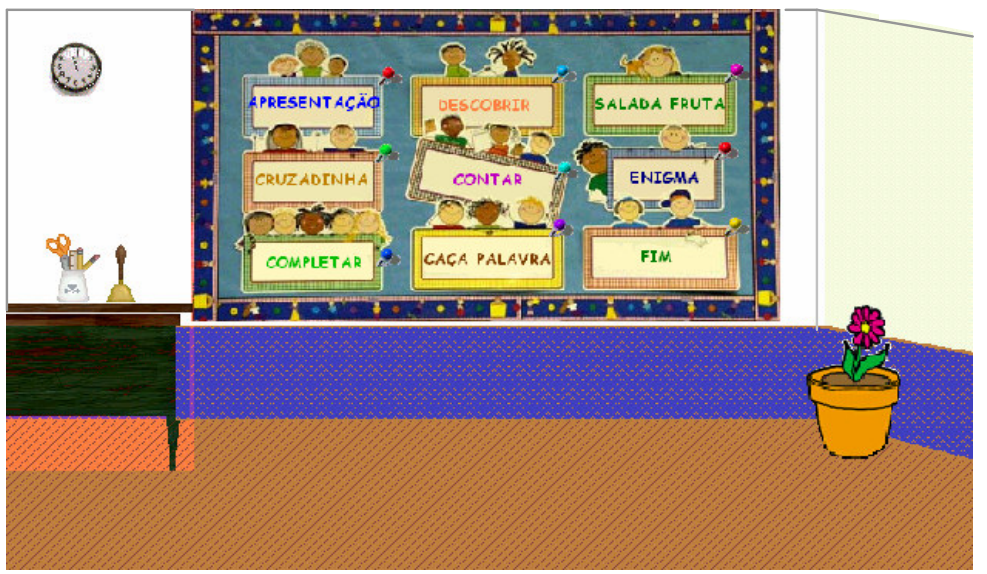

Figura 3 - Tela Menu da aplicação com atividades diversas para as séries iniciais

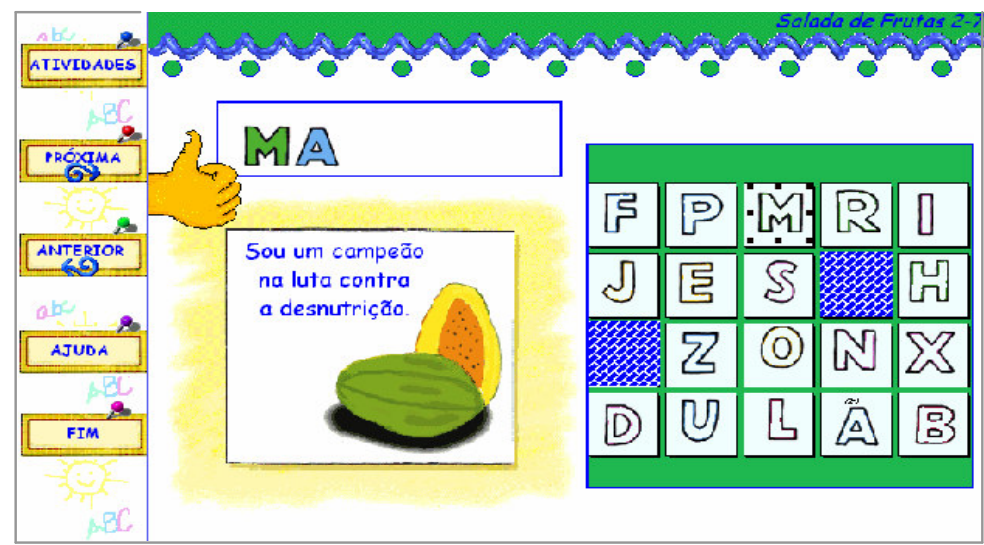

Figura 4 - Tela da opção Salada de Frutas 
Essa atividade faz com que o aluno desenvolva o raciocínio lógico e a memorização ao identificar as letras que correspondem ao nome da figura. Serve também para o aluno identificar o valor nutritivo das frutas.

$3^{\mathrm{a}}$ aplicação - são atividades digitais propostas com o objetivo de incentivar o desenvolvimento de práticas pedagógicas inovadoras, modificando a dinâmica do ensino, as estratégias e o comprometimento de alunos e professores. As atividades incluem a fase pré-silábica, a silábica e a alfabética. A aplicação propicia uma aprendizagem significativa, possibilitando ao professor explorar as atividades de diversas formas fazendo com que o processo de ensino e aprendizagem seja dinâmico e motivador. As atividades são variadas incluindo exercícios de reconhecimento de sílabas e as Cruzadinhas com todas as sílabas básicas.

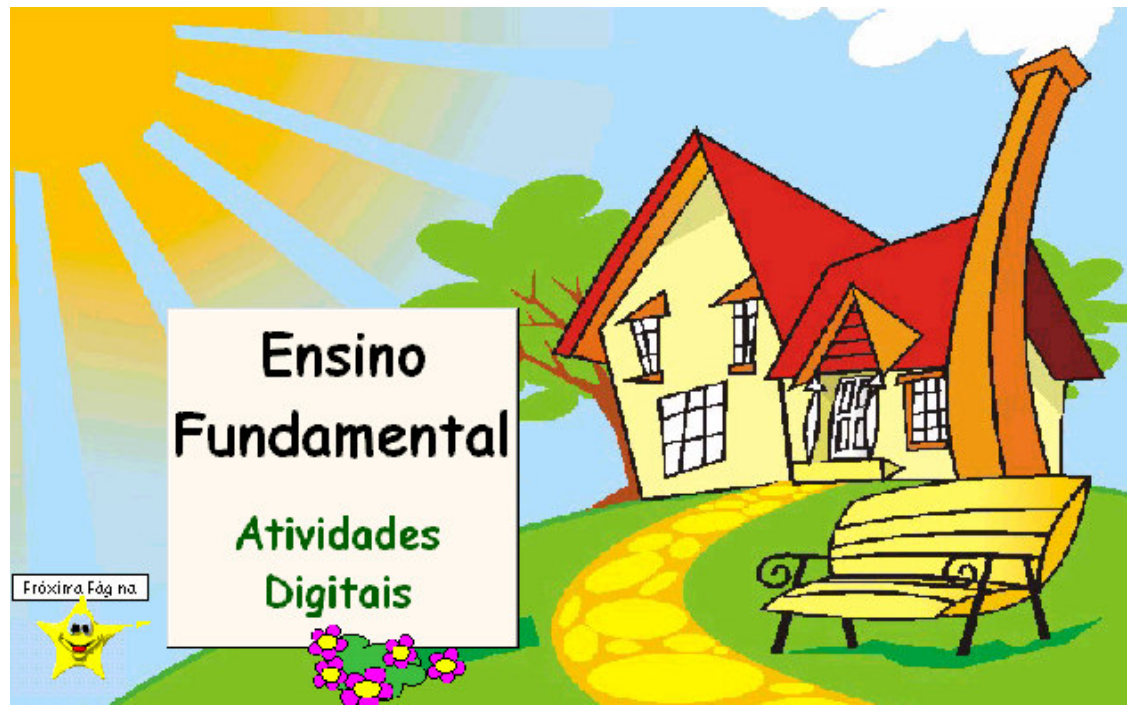

Figura 5 - Tela de apresentação das Atividades Digitais

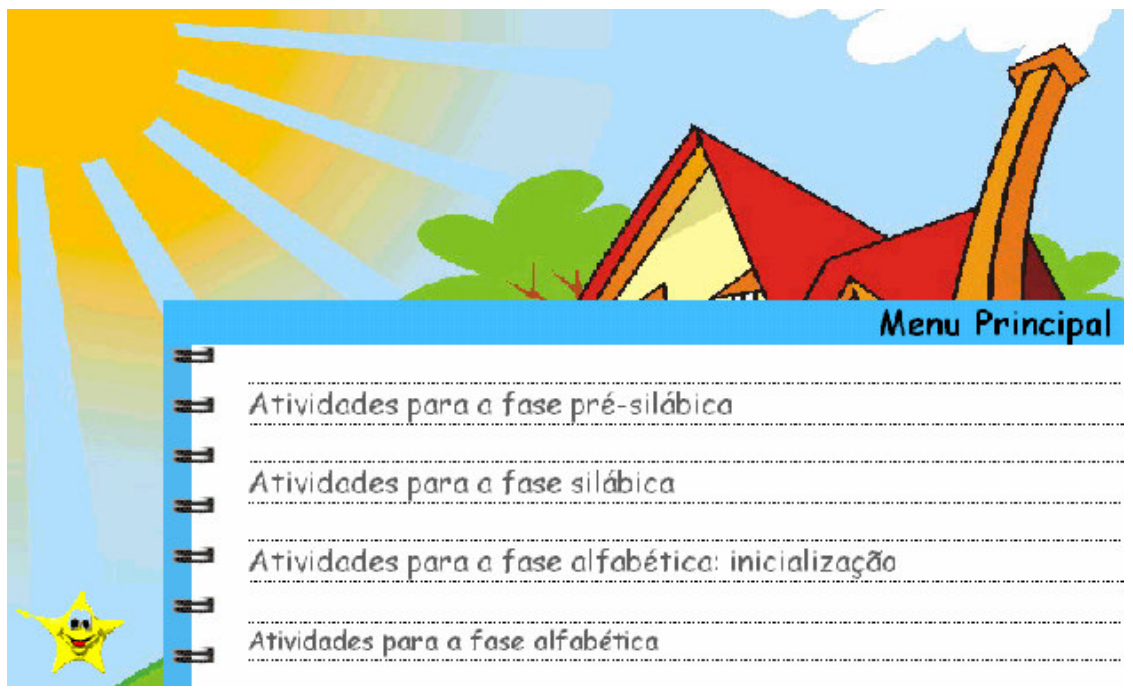

Figura 6 - Tela do Menu Principal 


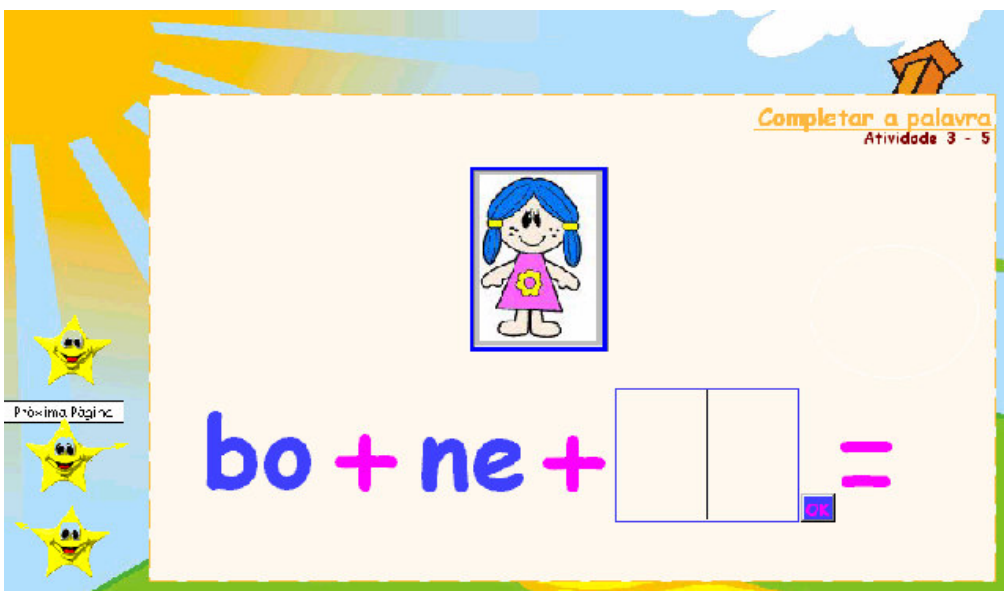

Figura 8: Tela da atividade: Completar a palavra da fase Silábica

\section{Conclusão}

Um material educativo bem concebido e utilizado de forma adequada oferece muitas vantagens, entre elas: fixa os conteúdos; permite a tomada de decisão; dá significado a conceitos de difícil compreensão; requer participação ativa; motiva; desperta a criatividade; a participação, e o prazer de aprender. $\mathrm{O}$ aluno deve conseguir, sem maiores dificuldades, entender as atividades propostas, os comandos mais elementares e as opções de navegação para se orientar rapidamente, sem dificuldades.

O desenvolvimento de um software educacional, ou seja, de uma aplicação hipermídia educativa normalmente envolve o esforço de profissionais das mais diversas áreas trabalhando em conjunto. A formação da equipe depende do tipo de aplicação a ser desenvolvida e da definição do tema. Inclui um profissional da área, um especialista em tecnologia educacional, um professor experiente, o projetista de mídias (imagem, som, vídeo) e um programador para, através de uma ferramenta de autoria, reunir todas as mídias e criar um material didático eficiente para o processo de ensino e aprendizagem tendo como meta dar subsídios ao aprendiz para construir o conhecimento conforme seu ritmo e de forma agradável. Porém, com as facilidades de uso dos sistemas de autoria é possível a criação de materiais didáticos digitais pelos próprios professores que tenham um conhecimento razoável das ferramentas de autoria.

Vale salientar que, os softwares educacionais são programas que visam atender necessidades vinculadas à aprendizagem, devem possuir objetivos pedagógicos e sua utilização deve estar inserida em um contexto e em uma situação de ensino baseados em uma metodologia que oriente o processo, através da interação, da motivação e da descoberta, facilitando a aprendizagem de um conteúdo.

Cabe ao professor estimular o aluno e direcioná-lo para os objetivos que a atividade se propõe. As atividades possibilitam ao professor criar interações e instigar o aluno despertando sua curiosidade. É, portanto, um bom instrumento para o professor, que pode propor o estudo de um tema de outra maneira e dar subsídios à criança para construir o seu conhecimento conforme seu ritmo, de forma agradável, agregando entretenimento, informação e ludicidade.

\section{Referências Bibliográficas}

ALAVA, Séraphin. Uma abordagem pedagógica e midiática do ciberespaço. Revista Pátio, RS, n.26, p.8-11. 2003.

ALMEIDA, M. E. Informática e Formação de Professores. ProInfo - Ministério da Educação. Secretaria de Educação à Distância. Brasília: vol. 1 e 2. 2000. 
ANTUNES, Celso. Como desenvolver conteúdos explorando as inteligências múltiplas. Petrópolis: Editora Vozes. 2003.

ANTUNES, Celso. Jogos para a estimulação das múltiplas inteligências. Petrópolis:Vozes. 1999.

ANTUNES, Celso. O jogo e a educação infantil. Rio de Janeiro: Vozes. 2003.

CORREA, Mafassioli Sonia Maria. Cartobrincando. o jogo original é o estudo de noções básicas sobre cartografia através de jogos, cujo objetivo é estabelecer as relações projetivas e serviu de base para a aplicação 1. Revista do Professor - ano XV - nº 57.

Rio Pardo: Editora CPOEC. 2000.

FERREIRO, Emilia. Reflexões sobre alfabetização - Porto Alegre: Artes Médicas. 1994.

FIGUEIREDO, Jakes Charles Andrade. Informática na Educação: “Novos

Paradigmas-

Universidade Federal de Mato Grosso do Sul. 2003.

FREIRE, F.M.P.e PRADO, M.E. Professores construcionistas: a formação em serviço, in Anais do VII Congresso Internacional Logo e I Congresso do Mercosul. Porto Alegre: LEC/UFRGS. 1995.

GROSSI, Esther Pillar. Série Didática Pós-Piagetiana: jogos para alfabetização. Erechim: Ed. Edelbra. 2001.

PAPERT, S. A máquina das crianças: repensando a escola na era da informática. Porto Alegre: Artes Médicas. 1994.

PIAGET, J. Teoria de Piaget. In: MUSSEN. Paul H. (org) Psicologia da criança. São

Paulo: EPU/ Edusp. 1975.

PIAGET, Jean. Epistemologia genética. São Paulo: Abril. 1978.

SILVA, Marco. Reinventar a sala de aula na cibercultura. Revista Pátio, RS, n.26, p.12-16. 2003.

TAJRA, Sammya Feitosa.Informática na Educação-Professor na Atualidade. São Paulo: Ed.Érica. 1998.

TEBEROSKY, Ana - Construccion de escrituras através de la intercacción grupal. São Paulo: Ed.Campus. 1994.

VALENTE, J. A. Diferentes Usos do Computador na educação. Computadores e conhecimento: Repensando a educação. NIED/ UNICAMP. 1995.

VYGOTSKI, L. S. A formação social da mente: o desenvolvimento dos processos psicológicos superiores. São Paulo: Martins Fontes. 1988. 